\title{
O PROCESSO DE DESENVOLVIMENTO DE PRODUTOS SOB A ÓTICA LEAN: A VARIÁVEL PRODUTO DO BENCHMARKING ENXUTO
}

\section{PRODUCT DEVELOPMENT PROCESS WITH LEAN FOCUS: PRODUCT VARIABLE IN BENCHMARKING ENXUTO}

\author{
Ana Julia Dal Forno ${ }^{1}$; Marcos Albuquerque Buson ${ }^{2}$; Claudio Gargioni Schuch ${ }^{3}$; Fernando Antonio \\ Forcellini $^{4}$; Marcelo Gitirana Gomes Ferreira ${ }^{5}$ \\ ${ }^{1}$ Universidade Federal de Santa Catarina - UFSC - Florianópolis - Brasil \\ anajudalforno@hotmail.com \\ ${ }^{2}$ Universidade Federal de Santa Catarina - UFSC - Florianópolis - Brasil \\ marcosbuson@gmail.com \\ ${ }^{1}$ Universidade Federal de Santa Catarina - UFSC - Florianópolis - Brasil \\ claudio.gargioni@gmail.com \\ ${ }^{1}$ Universidade Federal de Santa Catarina - UFSC - Florianópolis - Brasil \\ forcellini@gmail.com \\ ${ }^{1}$ Universidade Federal de Santa Catarina - UFSC - Florianópolis - Brasil \\ marcelo.gitirana@gmail.com
}

\begin{abstract}
Resumo
O Benchmarking Enxuto (BME) é um método baseado na ferramenta de benchmarking, que utiliza conceitos Lean para diagnosticar o estado atual do sistema produtivo de uma empresa. Este método, desenvolvido na Universidade Federal de Santa Catarina é baseado no Benchmarking Made in Europe (MIE). O presente artigo conceitua este método e apresenta um case de aplicação, mostrando o resultado do BME. Observando o sucesso no seu emprego, é proposto o desdobramento do questionário de BME com foco no produto, para aprimoramento da ferramenta e refinação dos dados. Isto possibilita um diagnóstico sobre a execução do planejamento, o papel dos stakeholders, o controle das atividades, sua implementação e como é medida sua performance, utilizando itens relacionados às variáveis de pesquisa do benchmarking enxuto, como foco na engenharia e planejamento do projeto. Como metodologia, o presente trabalho utiliza o método descritivo de um estudo de caso em uma montadora de placas de circuito impresso, para que se possa desenvolver uma correlação entre a teoria apresentada e a prática.
\end{abstract}

Palavras-chave: Lean, Planejamento do Projeto, Benchmarking, Processo de Desenvolvimento de Produtos.

\section{Introdução}

Um dos desafios da manufatura enxuta é obter vantagem competitiva agregando valor ao produto, e buscando a perfeição do processo, reduzindo ao máximo os desperdícios na linha de 
produção. O Diário Catarinense apud Dal Forno (2008) menciona a implantação da produção enxuta pelas empresas catarinenses, visando enfrentar a concorrência cada vez maior no mercado mundial.

Uma forma de se medir "o quanto" o sistema de produção é enxuto, é a aplicação de um questionário de Benchmarking Enxuto, que define o diagnóstico do estado atual do sistema produtivo, e a partir deste ponto, conhecem-se quais fatores são mais importantes para aplicar as melhorias voltadas à filosofia Lean na empresa.

Esta filosofia tem sido aplicada em outros setores de uma empresa, buscando um Processo de Desenvolvimento de Produtos (PDP) mais eficaz. Um PDP bem estruturado é capaz de surpreender o cliente e gerar bens de consumo capazes de atender as suas necessidades da melhor forma possível. Para a empresa gera vantagens competitivas no mercado, haja vista que este processo é a espinha dorsal de uma companhia que compete por meio de produtos próprios. Acredita-se que em torno de $85 \%$ dos custos do ciclo de vida dos produtos vêm de definições da fase de projeto. Da mesma forma, um PDP bem estruturado pode reduzir em 50\% o tempo de lançamento de um produto, identificando problemas de projeto e fazendo as alterações com antecedência. $\mathrm{O}$ ganho é de tempo, e de custos também, pois esta boa estruturação evita o "efeito escala", onde o custo das alterações aumenta em progressão geométrica de 10 a medida que se avança nas fases do projeto. (ROZENFELD et. al., 2006).

Desta forma, observa-se a oportunidade de se desenvolver um método de BME focado para a variável Produto, sendo esta, a proposta final do presente estudo.

\subsection{Objetivo e Metodologia}

O presente estudo possui três objetivos: conceituar o Benchmarking Enxuto (BME), apresentando como surgiu a idéia e as variáveis que o questionário engloba. Dentro desta conceituação também incluem-se os níveis de cada pontuação (básico, intermediário e avançado), apresentando o resultado de sua aplicação através de um estudo de caso com gráficos de radar, performance versus práticas e gráfico de barras. Com base na aplicação prática na empresa do ramo eletrônico, propõe-se como terceiro objetivo o desdobramento do questionário de BME com foco no produto, para aprimoramento da ferramenta e refinamento dos dados. $\mathrm{O}$ detalhamento visa atender de forma mais detalhada as variáveis que influenciam no Desenvolvimento do Produto, criando métricas para que ele também seja enxuto, e desta forma, agregue mais valor ao produto, reduzindo tempo e custo do projeto por meio da eliminação dos desperdícios e da otimização dos recursos humanos e físicos.

De acordo com o formato adotado para o método, os indicadores a serem medidos dentro de 
cada uma das variáveis estão divididos entre indicadores de prática gerenciais e operacionais e indicadores das performances obtidas. O primeiro grupo de indicadores citado está relacionado com ferramentas, técnicas gerenciais e tecnologias implementadas no sistema produtivo; enquanto que a performance é o resultado mensurável das práticas obtidas. Ao longo do trabalho serão detalhados e explicados através de um estudo de caso.

Para Yin (2001), um estudo de caso é uma investigação empírica que trata de um fenômeno contemporâneo dentro do seu contexto de vida real, em que múltiplas fontes de evidência são usadas. O presente trabalho utiliza o método descritivo, para que se possa desenvolver uma correlação entre a teoria apresentada e o estudo de caso em uma empresa de manufatura. Referente ao método do Benchmarking Enxuto, o seu procedimento de aplicação está descrito na tese de Andrade (2007).

\section{Filosofia Lean}

A essência da filosofia Lean é aproveitar ao máximo a capacidade produtiva para criar valor aos clientes, ocupando plenamente os recursos investidos em máquinas, equipamentos, instalações, materiais e pessoas. Inicialmente, deve-se elaborar o mapa do fluxo de valor para uma família de produtos. O projeto do estado futuro e o plano de ação indicarão as melhorias necessárias para fazer o produto fluir, sem esperas e retrabalhos. Assim, a empresa produzirá apenas o suficiente, reduzindo os lead times e os níveis de estoques quando necessário. Para viabilizar isso, são necessários:

a) esforços para aumentar a disponibilidade das máquinas e de equipamentos mediante manutenção adequada;

b) a solução imediata de problemas;

c) a troca rápida de ferramentas para facilitar as mudanças de modelos.

Essa redução dos estoques (e dos lead times) implicará maior capacidade de resposta e liberará espaço físico antes improdutivo, pois era usado para abrigar estoques em excesso. A melhoria dos níveis de qualidade, com a adoção de práticas da qualidade construída no processo, e a correta utilização do trabalho padronizado e do nivelamento também servirão para liberar capacidade e reduzir custos.

Com isso, será possível produzir o dobro do volume original com as mesmas máquinas, equipamentos e pessoas, e ainda com custos menores, menos área ocupada e melhor qualidade. Há na sociedade e no governo um forte desejo de ampliar os investimentos para fazer crescer a economia, mas devemos ser capazes de enxergar que investir, ampliar e contratar sem as precauções 
apontadas pode significar simplesmente um "inchaço" das empresas, sem efetivos ganhos de eficiência. Ao utilizar os conceitos Lean, as empresas podem adiar ou reduzir os investimentos em um primeiro momento. Com isso, haverá um substancial aumento da produtividade para as empresas e para a economia como um todo, no médio e no longo prazo, o que garantirá uma efetiva retomada do crescimento econômico e aumento do emprego em bases muito mais sólidas e sustentáveis (FERRO, 2008).

O sucesso da utilização do Sistema Toyota é devido às inúmeras vantagens que ele proporciona, confirmadas por Ferreira (2004):

a) Custos - dados os preços já pagos pelos equipamentos, materiais e mão-de-obra, a Manufatura Enxuta busca que o custo desses fatores seja reduzido ao essencialmente necessário;

b) Qualidade - o projeto do sistema evita que os defeitos fluam ao longo do processo, sendo os trabalhadores treinados para identificar os defeitos e encontrar métodos de solucioná-los e de evitá-los;

c) Flexibilidade - como a redução nos tempos envolvidos no processo, a flexibilidade ocorre em relação às variações do mix de produtos;

d) Velocidade - a flexibilidade, o baixo nível de estoques e a redução dos tempos permitem que o ciclo de produção seja curto e que o fluxo seja veloz. A prática de diferenciar os produtos na montagem final, a partir de componentes padronizados, permite entregar os produtos com prazos mais curtos; e

e) Confiabilidade - a confiabilidade das entregas é aumentada por meio da ênfase na manutenção preventiva e da flexibilidade dos trabalhadores. As regras do kanban e o gerenciamento visual permitem identificar rapidamente os problemas que poderiam comprometer a confiabilidade.

\section{Histórico do Benchmarking}

O interesse pelo potencial do benchmarking como modelo de identificação de oportunidades de aumento da competitividade de uma empresa data do final da década de 1970 e tem como marco o estudo realizado pela Xerox Corporation, que buscou nessa época conhecer as práticas empresariais japonesas.

Enquanto benchmark é definido como sendo o padrão de referência, o termo "benchmarking" representa o processo de comparação. O sucesso do benchmarking como modelo para alcançar uma vantagem competitiva depende da capacidade da empresa de adaptar criativamente as melhores práticas existentes no mercado, em vez de copiá-las cegamente (CAMP, 1997).

O Benchmarking Enxuto (BME) é um método, focado na ferramenta de benchmarking, para diagnóstico do estado atual do sistema produtivo, desenvolvido pelo Laboratório de Simulação de 
Sistemas de Produção (LSSP) da Universidade Federal de Santa Catarina, que busca dar suporte à implantação da Manufatura Enxuta. Ele é usado como diagnóstico inicial nas empresas, ou seja, para responder a questão “onde estamos?" ou então em conjunto com a ferramenta do Mapeamento do Fluxo de Valor. Quando aplicado após a implementação da Manufatura Enxuta, por exemplo, a empresa utiliza o BME no planejamento estratégico, para definir a questão "para onde vamos?". Assim, é um método de avaliação de desempenho com 37 indicadores que comparam a empresa avaliada em relação às variáveis Demanda, Produto, Planejamento e Controle da Produção (PCP) e Chão de Fábrica. A pontuação varia de 1 até 5, sendo que o nível mínimo é o básico e a nota 5 refere-se ao padrão da Toyota, pioneira das técnicas enxutas (DAL FORNO, 2008).

O método é baseado no Benchmarking Made in Europe (MIE), que surgiu da discussão de como a Europa estaria posicionada em relação ao padrão denominado classe mundial, em aspectos como custo, qualidade, flexibilidade e atendimento ao cliente. Em 1993, a London Business School lançou, em cooperação com um grupo de consultoria da IBM, uma iniciativa para realizar o MIE como um programa para medir o nível de práticas classe mundial e performance operacionais resultantes da adoção dessas práticas em empresas industriais européias (SEIBEL, 2004).

Os novos produtos resultantes do processo de desenvolvimento têm fortes impactos no desempenho do processo produtivo, dado que as características dos produtos refletem na fabricabilidade deles. Martins e Laugeni (2006) relatam estudos feitos demonstrando que a maioria - até $80 \%$ - dos problemas de qualidade decorre do projeto do produto, e não dos processos produtivos. Projetar produtos destinados a facilitar a manufatura vai ao encontro da linha de pensamento "fazer mais com menos", que guia os objetivos da ME. O projeto enxuto busca simultaneamente atender à demanda de variedade sem, no entanto, gerar uma ampliação desmedida do número de diferentes insumos que compõem os produtos finais, que deve ser fruto da aplicação do conceito de Engenharia Simultânea. Como forma de investigar o grau de desenvolvimento do sistema produtivo, em relação às práticas e performance alcançadas dentro do processo de projeto do produto, são propostos os seguintes indicadores de prática e indicadores de performance, resumidos na Figura 1. 
Figura 1 - Descrição dos Indicadores do Benchmarking Enxuto: Variável Produto

\begin{tabular}{|c|c|c|c|}
\hline \multicolumn{4}{|c|}{ Indicadores - Estuda do Produto } \\
\hline \multicolumn{2}{|r|}{ Prádicas } & Descriçäu & Tipu \\
\hline PRO1 & $\begin{array}{l}\text { Engenharia } \\
\text { Simultânea }\end{array}$ & $\begin{array}{c}\text { Avaliar o quanto a empresa pratica os conceitos da } \\
\text { Engenharia Simultânea }\end{array}$ & Geral \\
\hline PRO2 & $\begin{array}{c}\text { Parametrização de } \\
\text { Projeto }\end{array}$ & $\begin{array}{c}\text { Avaliar se existem parâmetros limitadores para o } \\
\text { desenvolvimento de produtos }\end{array}$ & Geral \\
\hline $\mathrm{PRO} 3$ & $\begin{array}{l}\text { Calendário de } \\
\text { Desenvolvimento }\end{array}$ & $\begin{array}{c}\text { Avaliar se existe um planejamento e organização no } \\
\text { processo de desenvolvimento de produtos }\end{array}$ & Geral \\
\hline $\mathrm{PRO} 4$ & $\begin{array}{l}\text { Negociaçẫo de } \\
\text { Pedidos Especia is }\end{array}$ & $\begin{array}{c}\text { Avaliar se a empresa adota políticas de aceitação de } \\
\text { pedidos especiais que năo prejudiquem o fluxo } \\
\text { de produção }\end{array}$ & Geral \\
\hline \multicolumn{2}{|c|}{ Pesformance } & Descrição & Tipo \\
\hline PRO5 & $\begin{array}{l}\text { Percentual de } \\
\text { Defeitos Intemos }\end{array}$ & $\begin{array}{l}\text { Medir o percentual de defeitos, normalmente } \\
\text { originados do projeto de produto }\end{array}$ & Esperifico \\
\hline PRO6 & Grau de Variedade & $\begin{array}{c}\text { Medir o grau de variedade e de itens existentes no } \\
\text { portfólio da empresa }\end{array}$ & Geral \\
\hline PRO7 & Ciclo de Vida & $\begin{array}{c}\text { Medir a relação entre o ciclo de vida e o lead time } \\
\text { produtivo dos itens }\end{array}$ & Geral \\
\hline PRO8 & $\begin{array}{l}\text { Percentual de } \\
\text { Sobra }\end{array}$ & $\begin{array}{l}\text { Medir a sobra de produtos em estoque ao final do } \\
\text { ciclo de vida do produto }\end{array}$ & Geral \\
\hline
\end{tabular}

Fonte: Andrade, 2007

\section{O Modelo Unificado}

A forma como a empresa organiza e desenvolve seus produtos depende de uma análise que deve considerar os seguintes fatores: a competitividade e as necessidades do mercado em que se encontra a empresa, a capacidade tecnológica e organizacional da própria empresa, e o desempenho do processo. Rozenfeld et al (2006) apresentam um modelo padrão para PDP voltado às empresas que desenvolvem produtos de bens de capital e consumo duráveis. Este modelo, é dividido em três macrofases: pré-desenvolvimento, desenvolvimento e pós-desenvolvimento. As fases, mostradas na Figura 2 de forma seqüencial, podem ser sobrepostas em um projeto real, e são determinadas pelas entregas de resultados e pelas avaliações finais de cada fase. 
Figura 2 - Modelo Unificado para o PDP

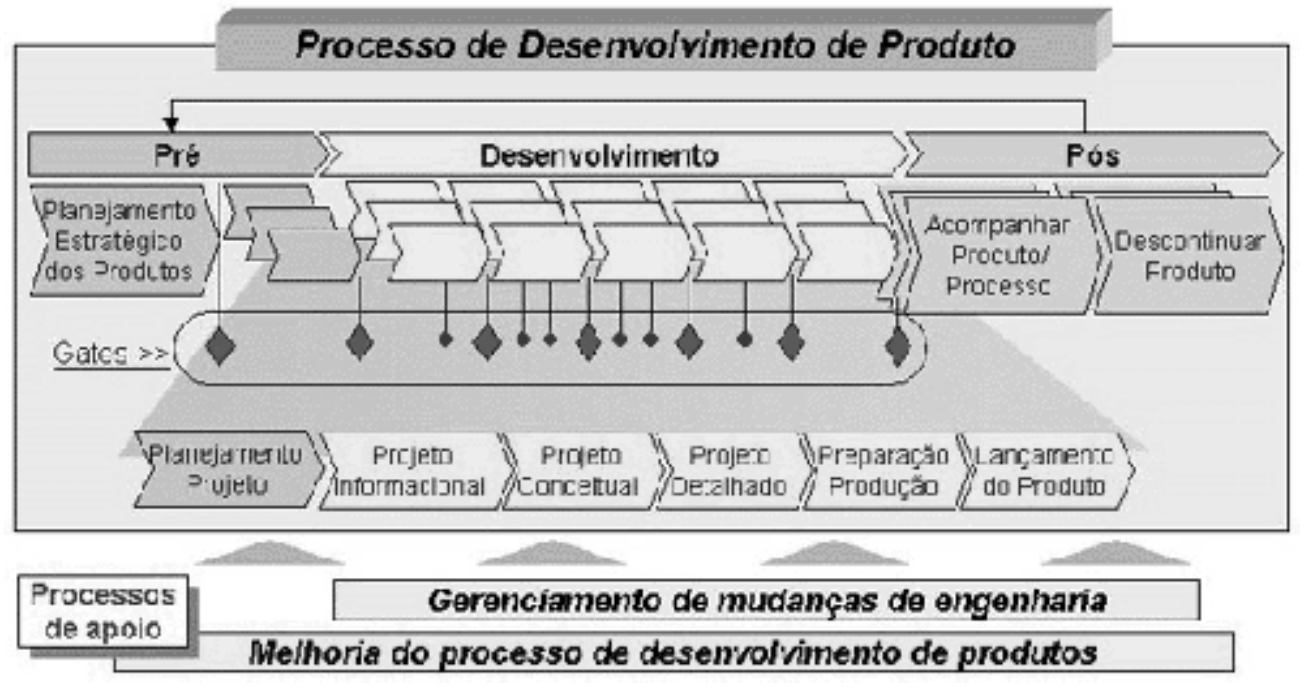

Fonte: Rozenfeld et al, 2006

O Pré-desenvolvimento envolve duas fases: o Planejamento Estratégico de Produtos, que agrupa as estratégias da empresa, e transforma isto em uma carteira de projetos, focados nas necessidades do mercado, na capacidade tecnológica e na estratégia da empresa. Esta fase é a única do modelo que envolve vários produtos, enquanto as outras fases são específicas para cada produto. A fase de Planejamento do Projeto, que será vista com mais detalhes a seguir, representa o planejamento mais detalhado de cada projeto de produto, cuja saída é o Project Charter ou o Plano do Projeto, documento que especifica como o projeto será executado, e desta forma, se ele é viável ou não às estratégias e às condições da empresa. O Pré-desenvolvimento é o que une os objetivos da empresa com os projetos de desenvolvimento.

A macrofase de Desenvolvimento é onde se transforma as idéias definidas e aprovadas no Pré-desenvolvimento, em produtos para consumo do mercado. Esta macrofase é tradicionalmente chamada de Projeto de Produto ou Desenvolvimento de Produtos, e define estratégias de desenvolvimento que vão de definir as necessidades dos clientes que o produto irá satisfazer, criar conceitos para este produto, selecionar os melhores conceitos, detalhá-los, testar virtualmente os conceitos, produzi-los, homologá-los e lançá-los no mercado. Estes procedimentos estão relacionados às fases de Projeto Informacional, Conceitual, Detalhado, Produção e Lançamento do Produto. Dependendo da situação do projeto, algumas atividades são feitas de forma a corrigir problemas ou adequar o produto às mudanças de mercado, e que tornam estas fases não totalmente seqüenciais, mas sim interagindo entre si durante toda a macrofase de Desenvolvimento.

O Pós-desenvolvimento engloba o acompanhamento do produto no mercado e os procedimentos para sua retirada, encerrando assim o ciclo de vida do produto. Este acompanhamento possibilita receber informações de como o produto reage ao mercado, com todos 
os processos de negócio envolvidos com o produto. Deste acompanhamento também podem surgir oportunidades de novos projetos relacionados a melhorias do produto ou correções de algum problema que não tenha sido previamente identificado, e que estão prejudicando seu desempenho no mercado, assim como também melhorias no próprio processo de desenvolvimento de produtos. Toda a documentação e avaliação do ciclo de vida obtidos garante que parte das pessoas e conhecimentos estejam à disposição da empresa, proporcionando sua reutilização em projetos de desenvolvimento futuros.

\section{A Fase de Planejamento de Projeto}

A literatura tem questionado sobre a necessidade e a forma de planejamento dos projetos. Segundo Chin (2004), o senso comum indica a necessidade de planejamento, apesar de ser um esforço que não adiciona o valor desejado ao produto, além do risco do plano em si prejudicar o andamento do projeto. Dvir, Raz e Shenhar (2003) apud Pessôa (2006) afirmam que o planejamento não garante o sucesso do projeto, mesmo que todo projeto necessite um planejamento e a falta dele provavelmente levará o projeto ao seu fracasso.

No entanto, a importância da fase se dá pela necessidade de entregar aos desenvolvedores, diretrizes e etapas essenciais ao desenvolvimento, ajudando-os a compreender a origem dos requisitos do projeto. (PAHL \& BEITZ, 1996). Pessôa (2006) também afirma que muitos defendem o planejamento de projeto, e destacam sua importância, especialmente nas áreas de definição e planejamento do cronograma, da engenharia de sistemas e da gerência de riscos. O PMBOK (2004) apresenta como objetivos do planejamento definir de forma clara os objetivos, definir também de forma clara o plano de ação necessário para atingir estes objetivos e completar o escopo que o projeto foi criado para atender.

Rozenfeld et. al. (2006) aponta que o planejamento, para a maioria dos projetos, pode ser executado apenas pelo gerente do projeto, apesar da possibilidade dele necessitar de ajuda de especialistas para realizar estimativas para alguns fatores.

De acordo com o modelo de referência (ROZENFELD et. al., 2006), a fase de planejamento de projeto recebe a proposta do produto, que vem do Portfólio de projetos e produtos, definido na fase anterior (Planejamento Estratégico de Produtos), e tem como saída um documento denominado de Plano de Projeto. Este plano deve conter a declaração do escopo do projeto e do produto, as atividades e sua duração, os prazos, orçamentos e pessoal responsável, os recursos necessários, a análise de riscos e indicadores de desempenho. Para chegar a tais informações, as atividades para o planejamento e suas dependências são apresentadas na Figura 3. 
Figura 3 - Informações principais e dependências entre as atividades da fase de Planejamento do Projeto

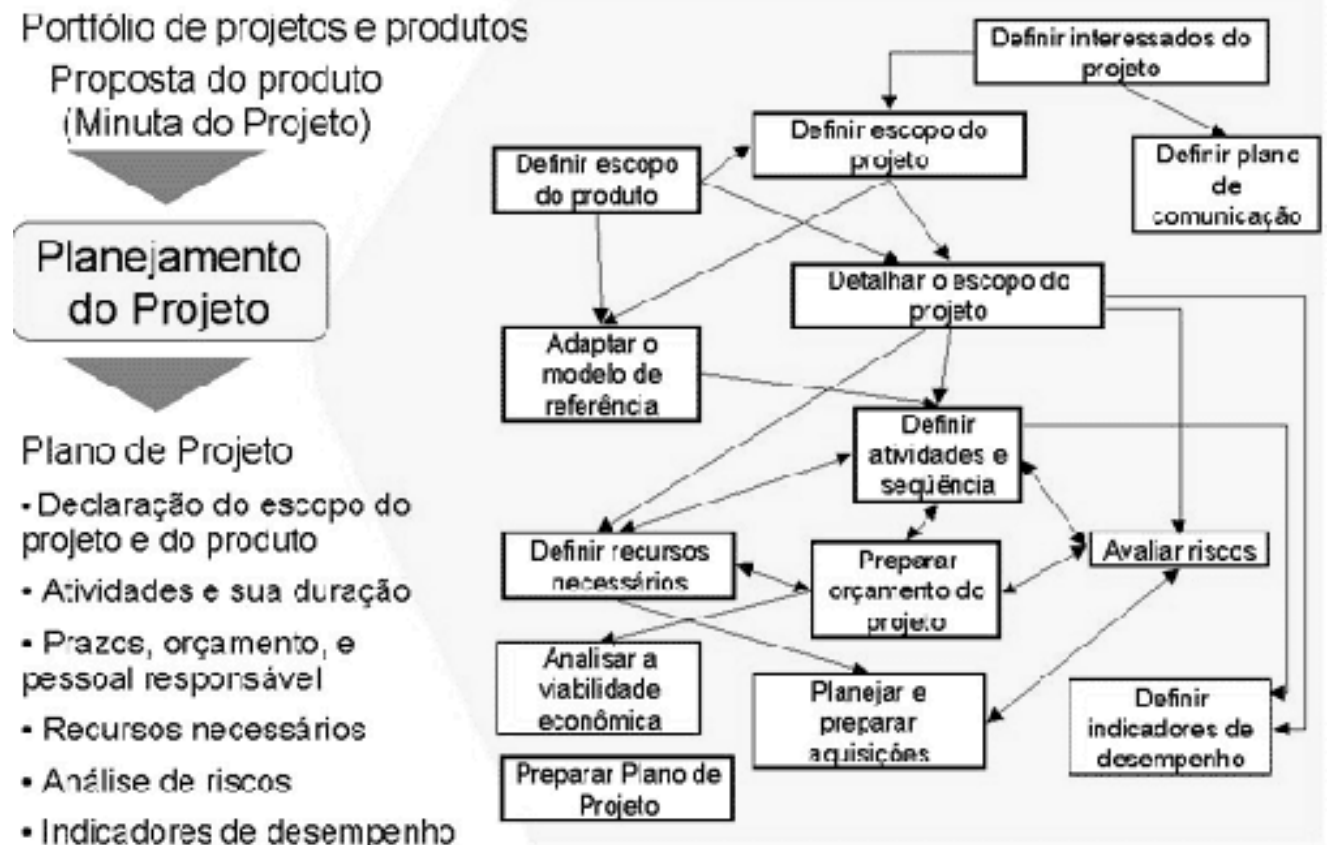

Fonte: Rozenfeld et al.,2006

\section{Apresentação da Empresa "Placas" e Descrição dos Processos}

A Empresa desse estudo de caso será genericamente denominada de "Placas". Correspondente ao ramo eletrônico, atua na montagem e soldagem de placas de circuito impresso (PCI) em grandes séries. Localiza-se em Florianópolis/SC desde 2002 e atualmente possui 90 funcionários e cerca de oito tipos de placas eletrônicas em seu portfólio. Em regime de parceria, utiliza a mesma planta de um "Laboratório Fábrica" de suporte à produção de pequenas séries de placas eletrônicas, que realiza atividades de capacitação, pesquisa, desenvolvimento, prototipagens e pré-séries.

O processo de fabricação da placa-mãe inicia-se na máquina de inserção automática, onde ocorre a aplicação da pasta de solda, inserção discreta SMD, inserção exata SMD, inserção BGA e soldagem por refusão. Após a inspeção elétrica - In Circuit Test -, as placas com problemas seguem para um setor específico de reparos, e as demais seguem para a macro-etapa de inserção manual, composta das seguintes fases: alimentação da linha, inserção manual dos componentes, soldagem por onda, acabamento, revisão de solda e PTH. Após, há o teste funcional em todo o lote, e as peças com qualidade são embaladas e expedidas.

De forma geral, a seqüência consiste no envio do pedido pelo cliente, assim como os kits de componentes (matéria-prima), que são conferidos e armazenados no almoxarifado. A partir do PCP, que emite a ordem de produção, o almoxarifado separa o material para a produção diária e 
transporta-o até cada posto de trabalho. Inicia-se o setup, maior gargalo existente na empresa, pois, para a montagem automática, é necessário programar onde deve ser montado cada componente. $\mathrm{Na}$ seqüência, a produção segue na máquina automática (SMD), e por fim as placas são inspecionadas de forma visual e por teste elétrico. Caso a placa tenha algum defeito, retorna ao processo inicial. As peças boas seguem o fluxo para a máquina de inserção manual (PTH), onde serão testadas e embaladas. Caso tenham defeito, passam pelo setor de consertos.

Uma das características do processo da Empresa "Placas", é que nem todas as placas seguem o mesmo fluxo de processo. Algumas passam pela máquina automática e manual juntamente, às vezes somente há inserção PTH e às vezes somente a SMD, ou, ainda, uma placa pode ter inserção nos dois lados (inserção Bottom e inserção Top), necessitando passar duas vezes pelo mesmo fluxo de processo. Convém lembrar que SMT e THT são referentes à tecnologia, enquanto SMD e PTH são relacionados aos componentes. Por exemplo, um componente SMD é montado no processo SMT.

\section{A aplicação da Variável Produto do Benchmarking Enxuto na Empresa de Placas de Circuito Impresso}

Para a aplicação da ferramenta Benchmarking Enxuto, esteve envolvida apenas a equipe de engenharia, responsável pelo desenvolvimento de projetos e tecnologias, mas que possui amplo conhecimento do processo produtivo. As informações foram sigilosas e não muito detalhadas, em virtude de a empresa ser fornecedora de multinacionais. De forma geral, em relação à Manufatura Enxuta, a empresa ficou posicionada no quadrante mais crítico - baixas práticas e baixas performances.

$\mathrm{Na}$ Figura 4, fica destacado através do gráfico radar que a Empresa "Placas" possui boas práticas de produto porque tem a ênfase na engenharia de projetos bem desenvolvida. Não existe um modelo de previsão de demanda, nem a gestão ABC para classificar os produtos; além disso, os graus de concentração e de freqüência são baixos e não há confiabilidade na previsão. O pedido que é confirmado é fabricado sem ter uma regra de prioridade definida. Há momentos em que é conforme o grau de importância do cliente, outros de acordo com a matéria-prima disponível e, às vezes, segue o FIFO (primeiro pedido que entra é o primeiro pedido que sai). 
Figura 4 - Gráfico radar da Empresa "Placas"

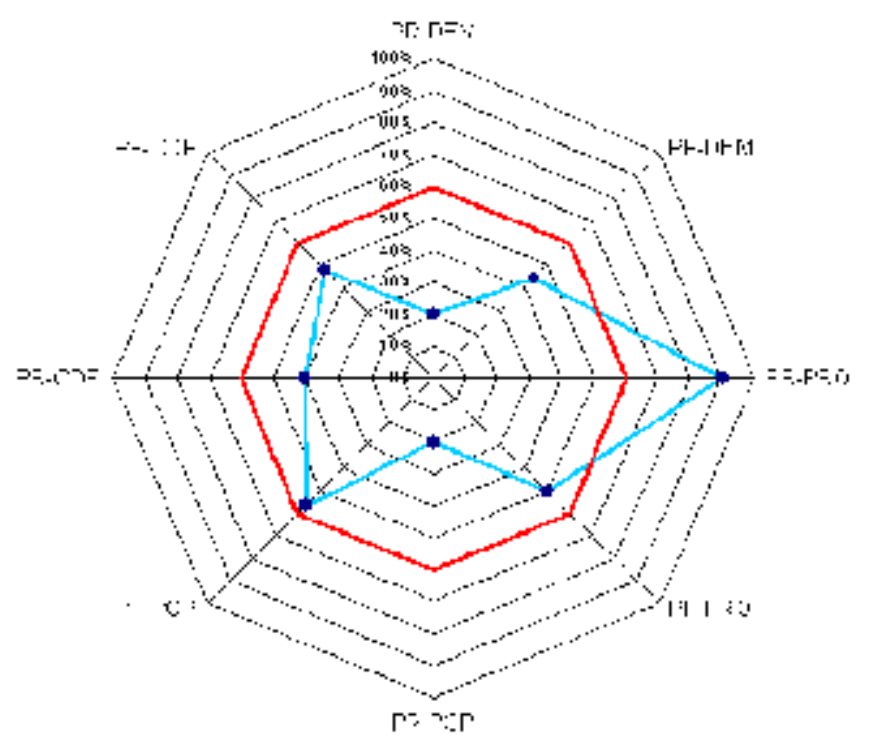

Fonte: Dal Forno, 2008

Seguindo o Benchmarking Enxuto, na Figura 5, há a descrição da nota de cada indicador de Produto - variável foco desse trabalho.

Figura 5 - Indicadores da aplicação do BME na Empresa Placas

\begin{tabular}{|c|c|c|c|c|c|c|}
\hline \multirow{4}{*}{ F'F } & getral & FRO-LII & Erıgeriliaria simultütriea & 5 & $1[1[1 \%$ & \multirow{4}{*}{$90 \%$} \\
\hline & gefd & $\mathrm{FRO}-\mathrm{Cl}$ & 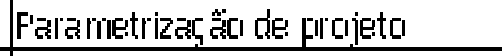 & 4 & $\mathrm{E}[\mathrm{C} \%$ & \\
\hline & gerd & $\mathrm{FFO}-\mathrm{ClO}$ & 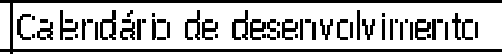 & 5 & $1[1] \mid \%$ & \\
\hline & getal & $\mathrm{FFIO-C14}$ & 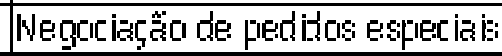 & 4 & $E[1 \%$ & \\
\hline \multirow{4}{*}{ F'F } & espectifica & FROI-[LI & F'elcelitual de defeitcas intelnas & 1 & $201 \%$ & \multirow{4}{*}{$50 \%$} \\
\hline & getrd & $\mathrm{FFO}$-[If: & Gl all de vestiedede & 1 & $2[1 \%$ & \\
\hline & gefral & $\mathrm{FFOO-[7]}$ & Ciclo de vida & 3 & $E_{1}[1 \%$ & \\
\hline & geral & F'FO-CIEI & F'el'cellitual de solitira & 5 & $1[1] 1 \%$ & \\
\hline
\end{tabular}

Fonte: Dal Forno, 2008

Em relação ao BME para a variável Produto, esta se mostrou mais bem posicionada, atingindo $90 \%$ de prática e $50 \%$ de performance. A estrutura para o projeto do produto é bem desenvolvida, envolvendo a participação de várias áreas multifuncionais para, no final, atender às necessidades dos consumidores. Slack et al. (2006) determinam que o produto é composto de três aspectos: um conceito, que é o conjunto de benefícios esperados que o consumidor está comprando; um pacote de produtos e serviços componentes, que proporcionam os benefícios definidos no conceito; e o processo, pelo qual a operação produz o pacote de produtos e serviços componentes. 
Dessa forma, esses passos são bem detalhados, e o indicador PRO-01 evidencia a excelência através da engenharia simultânea. Entretanto, ao observar a Figura 6, o percentual de defeitos internos (PRO-05) é alto, evidenciando o desequilíbrio entre os setores de projeto de produto e a produção. Quanto a esse indicador, na empresa o índice de defeitos está em 12\%, enquanto o cliente permite no máximo $2 \%$, sendo o padrão do BME de $0,01 \%$.

Olhando a empresa como um todo e considerando que $25 \%$ da utilização da planta é destinada à pesquisa e desenvolvimento, Slack et al. (2006) reforçam esse indicador com o dado de que 5,8\% das vendas são gastos com P\&D no ramo eletrônico, ficando atrás apenas das indústrias farmacêutica $(16,1 \%)$, de serviços e saúde $(9 \%)$ e da indústria de equipamentos de escritório e serviços $(8,3 \%)$.

Figura 6 - Indicadores da variável Produto na Empresa "Placas"

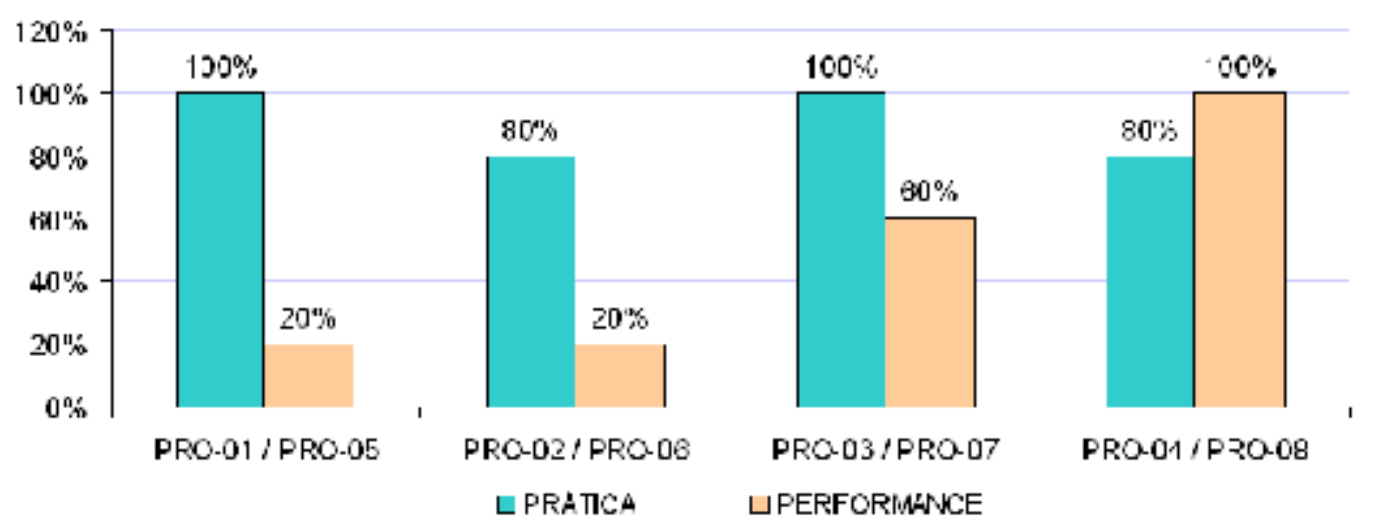

Fonte: Dal Forno, 2008

Justificando, o indicador PRO-02 reforçou que há parâmetros de projetos bem definidos, com prazos de execução, check-lists, da idéia ao conceito, passando pela prototipagem. Porém, é preciso ter o cuidado para não gerar um excesso de documentos, o que pode retardar o lançamento de um produto. Em contrapartida, o indicador PRO-06 pontuou com nota 1, entendendo-se como o número de itens dentro da família cada componente que compõe a placa de circuito impresso, que geralmente são centenas. Como ponto forte da variável Produto na Empresa "Placas", PRO-03 foi um indicador que atingiu a excelência, mostrando que há um calendário bem definido para o desenvolvimento de todos os novos produtos, projetos planejados através de parcerias com outras instituições que queiram tecnologias no ramo eletrônico. PRO-07 situou-se no nível intermediário, tendo-se considerado em média a vigência de um portfólio de três anos.

Conforme já descrito, como há a parametrização de projeto e considerando os pedidos como especiais, tanto de pequenas como grandes séries, para PRO-04 os pedidos automaticamente são 
especificados, sendo esse o procedimento padrão na Empresa "Placas". Tratando da sobra (PRO08), principalmente de produto acabado, isso não ocorre neste estudo de caso. Assim, a empresa pontuou com a excelência, sendo o seu problema divergente: quando a taxa de defeitos está fora dos padrões estabelecidos pelo cliente, e considerando que ele envia os kits de componentes para a montagem, o percentual de sobra classificar-se-ia como negativo; faltam placas na expedição.

\section{O Benchmarking Enxuto como objeto de estudo a variável Produto}

Entende-se que o BME é uma ferramenta de posicionamento eficaz, porém para uma maior precisão de dados, principalmente no contexto de planejamento do projeto, é necessário uma remodelagem e o acréscimo de questionamentos e índices intrínsecos ao PDP. O objetivo desse foco é possibilitar um diagnóstico por meio de coleta de informação sobre a execução do planejamento, o papel das pessoas envolvidas no processo, o controle das atividades, sua implementação e como é mensurada sua performance utilizando itens relacionados às variáveis de pesquisa de Produto do BME. O diferencial dessa avaliação é o desmembramento do quesito Produto do BME em sub-tópicos, aprofundando-se no tema buscando maior precisão nos dados e mapeando o valor no fluxo de informação desde o início do ciclo de vida, e ampliando o foco de pesquisa do pensamento filosofia Lean para o planejamento.

De acordo com o formato adotado para o método, os indicadores a serem medidos dentro de cada uma das variáveis ainda serão divididos entre indicadores de práticas gerenciais e operacionais e indicadores das performances obtidas.

A proposta de avaliação em empresas tem como foco a elaboração de um diagnóstico da fase de Planejamento e Desenvolvimento de Produtos sob uma ótica dos princípios da filosofia Lean. Essa abordagem comparativa tem como parâmetros o desempenho de uma empresa Classe Mundial, dentre elas a Toyota, que segue um desenvolvimento de produtos e manufatura puxados.

Os parâmetros de avaliação utilizam o fluxo de informações, presente no Desenvolvimento de Produtos, especificamente nas fases de Planejamento do Projeto, Projeto Informacional e Projeto Conceitual, conforme a Figura 7. Essas fases são essenciais e têm impactos críticos nas fases de detalhamento e produção. É recomendado e preferível que essa empresa já tivesse passado por um Benchmarking Enxuto para ter o diagnóstico dos pontos fracos e fortes e a partir disso, definir as prioridades de atuação, conforme as variáveis de Demanda, Produto, PCP e Chão de Fábrica. Após aplicado o BME e implementadas as melhorias, o ciclo PDCA reinicia, seguindo a filosofia Kaizen de melhoramento contínuo. 
Figura 7 - Ciclo de vida do Projeto e do Produto, com detalhe no Planejamento do Projeto, Projeto Informacional e Projeto Conceitual

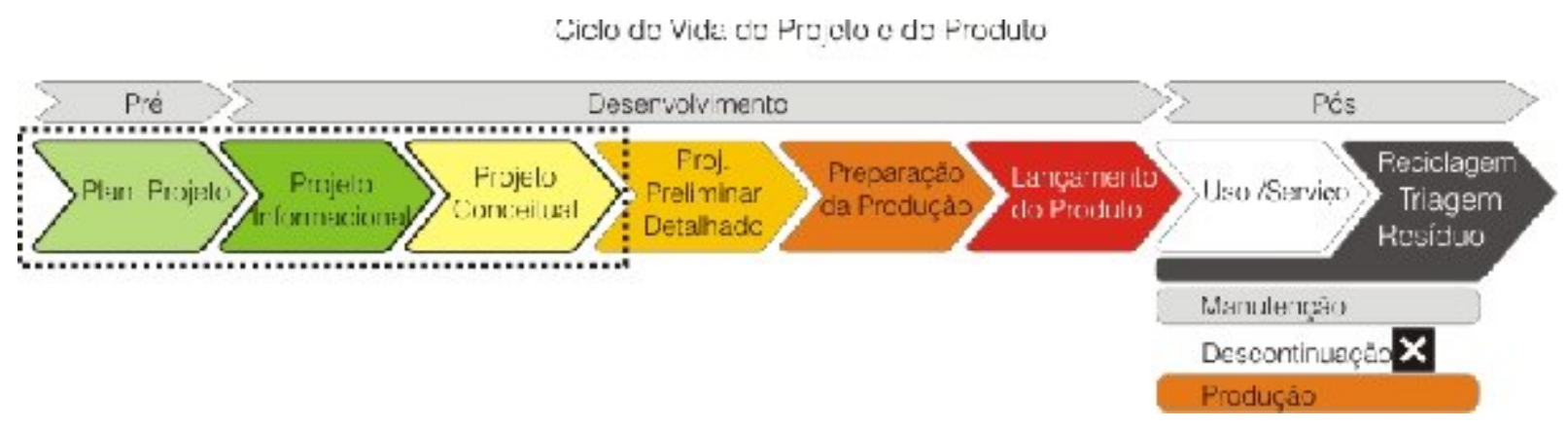

Fonte: Adaptado de Larson \& Gobeli, 1988; Rozenfeld, et al., 2006

Outras referências também buscaram a avaliação de sistemas e processos, ou seja, de fluxo de material ou de informação, com o objetivo sempre de eliminar desperdícios, buscando assim melhores resultados. Exemplos de aplicação estão em Binnersley (1996) que direcionou sua avaliação para os processos-chave de negócio e também Graddy (1991) e Walsh (1996) que relacionavam dados de resultados e processos. Nesses casos são ressaltados as relações entre tempo/qualidade/custo e resultado alcançado, onde existem também ferramentas de apoio à decisão que possibilitam uma melhor escolha se adequando a cada contexto.

O trabalho proposto permite fazer uma avaliação que não possui um conceito meramente comparativo. O objetivo é estabelecer um perfil da empresa com base na coerência de seu funcionamento com relação aos princípios Lean, com foco tanto a visão pontual de ferramentas e técnicas tanto um panorama global do processo de desenvolvimento de novos produtos. Por fim, almeja-se gerar um coeficiente utilizado como parâmetro empresas Classe Mundial, que significa ressaltar a discrepância e o caminho a ser seguido para a incorporação da filosofia Lean.

\section{Considerações Finais}

Como ressaltaram Fortuin (1988) e Kaplan (1991), a avaliação de resultados no âmbito de eficiência e eficácia no processo de negócio é a mais indicada em uma visão holística de processo de ciclo de vida de projeto e produto. A divisão do questionário busca identificar se o processo é controlado ou se seus resultados têm como case processos empíricos, ou seja, se existem resultados construídos por meio de processos estabilizados ou resultados atingidos ao acaso. A intenção desse rótulo de performance trata de vislumbrar a longo prazo a sustentabilidade da eficácia do PDP, possibilitando assim identificar os pontos fortes e direcionar os esforços nos pontos vulneráveis.

Através do método do Benchmarking Enxuto é possível identificar os pontos fortes e fracos 
das variáveis: Demanda, Produto, PCP e Chão de Fábrica. O foco desse trabalho foi detalhar e avaliar o segundo grupo de indicadores, referente ao escopo de Desenvolvimento de Produtos Lean. A Aplicação prática pode ser replicada a demais tipos de manufatura e/ou serviços, dentre elas empresas de base tecnológica, escritórios de projetos e núcleos de pesquisa em universidades. Entende-se que ao elencar as ferramentas de qualidade que guiam o projeto informacional, busca-se dar um direcionamento sobre como e onde são aplicadas as práticas e com isso executá-las em novas empresas que estão aderindo ao pensamento enxuto.

Desenvolver produtos com base nas necessidades latentes dos consumidores é um princípio da filosofia Lean, entretanto a prospecção do próximo passo é realmente o desafio. Esse salto, que não é obrigatoriamente tecnológico ou estético, é crucial para a sobrevivência da corporação. Rozenfeld (2006) refere-se a esses projetos como radicais, onde envolvem significativas modificações no projeto do produto ou processo existente.

E, ao passo que o processo de inovação possui o fluxo de informações em maior volume em relação ao fluxo de material, é necessário em termos acadêmico e mercadológico que estudos que pretendem controlar e mensurar de índices de performances dos dados, sempre sejam objetos de pesquisa. No detalhamento do Benchmarking Enxuto focado ao PDP, serão mapeadas questões como: há um responsável o projeto de cada família de produtos? Qual o grau de relacionamento dos fornecedores? Qual o fluxo das informações? Há um modelo de referência, um padrão para o lançamento de novos produtos? O escopo do projeto é fixo? Definido com o cliente? Há fases de revisão e onde situam-se? Qual o grau de envolvimento de cada nível hierárquico? Enfim, esses questionamentos caracterizam-se como diferenciais para evitar que um produto seja lançado de forma que não atenda aos requisitos solicitados pelo cliente. Através do processo de criação conjunta, ou seja, com a engenharia simultânea, a estrutura de comunicação instalada suportará o desenvolvimento em conjunto de um projeto que vislumbre simultaneamente os aspectos particulares de cada setor ou função envolvida.

\begin{abstract}
The Benchmarking Enxuto(BME) is a method based on the Benchmarking tool, which uses Lean concepts to diagnose the production system status of a company. This method, developed at the Federal University of Santa Catarina is based Made in Europe (MIE) Benchmarking. This article conceptualized this method and presents a case study, showing the results of BME. After, identifying and knowing the success of its application, it is proposed to split the BME questionnaire to focus on product indicators, for improving the tool itself and refining the resultant data. This approach enables a diagnosis on the planning implementation, the role of the stakeholders, activities control, their implementation and how their performance is measured using items related to lean benchmarking research variables, with focus on engineering and project planning. As a methodology, this paper uses the method presented in a case study in a printed circuit boards assembler in order to develop a correlation between the presented theory and practice.
\end{abstract}

Key-words: Lean, Project Planning, Benchmarking, Product Development Process. 


\section{Referências}

ANDRADE, G. J. P. O. Um método de diagnóstico do potencial de aplicação da Manufatura Enxuta na indústria têxtil. Tese (Doutorado em Engenharia de Produção) - Programa de Pós-Graduação em Engenharia de Produção, Universidade Federal de Santa Catarina, Florianópolis, 2007

BINNERSLEY, M. Do you measure up? Management Accounting. November, 1996. pp. 32-34.

CAMP, R. O aprendizado pelo benchmarking. HSM Management, n. 3, July/Aug. 1997.

CHIN, G. L. Agile Project Management: How to Succeed in the Face of Changing Project Requirements. Amacon, 2004.

DAL FORNO, A. J. Aplicação e Análise das Ferramentas Benchmarking Enxuto e Mapeamento do Fluxo de Valor: Estudo de Caso em três empresas catarinenses. Dissertação (Mestrado em Engenharia de Produção) Programa de Pós Graduação em Engenharia de Produção, Universidade Federal de Santa Catarina, Florianópolis, 2008.

FERREIRA, F. P. Análise da implantação de um sistema de Manufatura Enxuta em uma empresa de autopeças. 2004. Dissertação (Mestrado em Engenharia de Produção) - Unitau, Taubaté, 2004.

FERRO, J. R. Crescer sem investir: estratégia lean de investimento. Disponível em: <www.lean.org.br>. Acesso em: 14 jan. 2008.

FIORE, C. Accelerated Product Development - Combining Lean and Six Sigma for Peak Performance. New York: Productivity Press, 2005.

FORTUIN, L. Performance indicators - why, where and how?. European Journal of Operations Research. V.34, 1988, pp.1-9.

GRADDY, M. W. Performance measurement: a review of current practice and emerging trends. International Journal of Operations \& Production Management, MCB University Press, Boston, v. 30, n. 1, p. 49-53, jun. 1991.

KAPLAN, R. S. New systems for measurement and control. The Engineering Economist, v. 36, n.3, 1991, pp. 201218.

LARSON, E. W. \& D. H. GOBELI. "Organizing for Product Development Projects." Journal of Product Innovation Management, 1988, 5, 180-190.

MARTINS, P. G.; LAUGENI, F. P. Administração da produção. 2. ed. São Paulo: Saraiva, 2006.

PAHL, G.; BEITZ, W. Engineering design: a systematic approach. Londres: Springer-Verlag, 1996.

PALADINI, E. P. Gestão da Qualidade: teoria e prática, São Paulo: Atlas, 2004. 339p.

PESSÔA, M. V. P. Proposta de um método para planejamento de desenvolvimento enxuto de produtos de engenharia. 2006. 266p. Tese de Doutorado em Engenharia Aeronáutica e Mecânica. Área de Produção - Instituto Tecnológico de Aeronáutica, São José dos Campos.

PMBOK. A guide to the project management body of knowledge. 3.ed. PMI-Project Management Institute, Newton Square, Pennsylvania, USA, 2004.

ROZENFELD, H., [et al.]. Gestão de Desenvolvimento de Produtos: Uma referência para a melhoria do processo. São Paulo: Saraiva. 2006.542 p.

SEIBEL, S. Um modelo de benchmarking baseado no sistema produtivo classe mundial para avaliação de práticas e performance da indústria exportadora brasileira. 2004. $172 \mathrm{f}$. Tese (Doutorado em Engenharia de Produção) - Programa de Pós-Graduação em Engenharia de Produção, Universidade Federal de Santa Catarina, Florianópolis, 2004.

SLACK, N. [et al.]; Administração da Produção. Edição compacta. Revisão técnica Henrique Côrrea e Irineu Gianesi.São Paulo: Atlas, 2006. 
WALSH, P. Finding key performance drivers: some new tools. Total Quality Management. East London Business School, University of East London Longbridge Road, Dagenham, n. 5, p. 9-19, 1996.

WOMACK, J.; JONES, D. T. Soluções Enxutas: como empresas e clientes conseguem juntos criar valor e riqueza. Rio de Janeiro: Campus, 2006.

YIN, R. K. Estudo de caso: planejamento e métodos. Porto Alegre: Bookman, 2001.

Nome completo: Ana Julia Dal Forno

Filiação institucional: UFSC - Universidade Federal de Santa Catarina

Departamento: Engenharia de Produção e Sistemas

Função ou cargo ocupado: Doutoranda em Engenharia de Produção, Pesquisadora do Grupo de Engenharia de Produto e Processo (GEPP).

Endereço completo para correspondência (bairro, cidade, estado, país e CEP): Rua João Pio Duarte Silva, 682 A4 304. CEP: 00837-000. Bairro Córrego Grande, Florianópolis/SC.

Telefones para contato: (48) 9617-7290; (48) 3721-7101

e-mail:anajudalforno@hotmail.com; anajulia@deps.ufsc.br

Nome completo: Marcos Albuquerque Buson

Filiação institucional: UFSC - Universidade Federal de Santa Catarina

Departamento: Engenharia de Produção e Sistemas

Função ou cargo ocupado: Doutorando em Engenharia de Produção, Pesquisador do Grupo de Engenharia de Produto e Processo (GEPP).

Endereço completo para correspondência (bairro, cidade, estado, país e CEP): Rua Embaixador Edmundo da Luz Pinto, 117. Bairro: Agronômica. Florianópolis/SC. Brasil. CEP 88025-050

Telefones para contato: (48) 8805-9111; 3721-7101

e-mail:marcosbuson@gmail.com

Nome completo: Claudio Gargioni Schuch

Filiação institucional: UFSC - Universidade Federal de Santa Catarina

Departamento: Engenharia Mecânica

Função ou cargo ocupado: Mestrando em Engenharia Mecânica, Pesquisador do Grupo de Engenharia de Produto e Processo (GEPP).

Endereço completo para correspondência (bairro, cidade, estado, país e CEP): Rua Altamiro Guimarães, 284, apt 301. Bairro: Centro. Florianópolis/SC.

Brasil. CEP 88015-510 
Telefones para contato: (48) 8822-6882; 3721-7101Telefones para contato: (48) 3721-7101

e-mail: claudio.gargioni@gmail.com

Nome completo: Fernando Antonio Forcellini

Filiação institucional: UFSC - Universidade Federal de Santa Catarina

Departamento: Engenharia de Produção e Sistemas

Função ou cargo ocupado: Doutor em Engenharia de Produção, Chefe de Departamento, Professor Associado I do DEPS.

Endereço completo para correspondência (bairro, cidade, estado, país e CEP):

Universidade Federal de Santa Catarina - Grupo de Engenharia do Produto e Processo -

Departamento de Engenharia de Produção e Sistemas - Centro Tecnológico - Caixa Postal 476 -

Campus Universitário - Trindade

CEP 88040-900 - Florianópolis/ SC - Brasil

Telefones para contato: (48) 3721-7041

e-mail:forcellini@deps.com.br,forcellini@gmail.com

Nome completo: Marcelo Gitirana Gomes Ferreira

Filiação institucional: UFSC

Departamento: Engenharia de Produção e Sistemas

Função ou cargo ocupado: professor voluntário

Endereço completo para correspondência (bairro, cidade, estado, país e CEP): Universidade Federal de Santa Catarina - Grupo de Engenharia do Produto e Processo - Departamento de Engenharia de Produção e Sistemas - Centro Tecnológico - Caixa Postal 476 - Campus Universitário - Trindade CEP 88040-900 - Florianópolis/ SC - Brasil

Telefones para contato: (48) 3721-7101/9106-9123

e-mail: marcelo.gitirana@gmail.com 